\title{
The effect of frequency of feeding on the flow and composition of duodenal digesta in sheep given straw-based diets
}

\author{
By F. THOMPSON* \\ Department of Physiology and Environmental Studies, \\ University of Nottingham School of Agriculture, \\ Sutton Bonington, Loughborough, Leics.
}

(Received 14 August $1972-$ Accepted 8 December 1972)

I. The effect of feeding sheep at two different frequencies (once hourly and once daily) on the flow of digesta, dry matter, and starch to the duodenum was assessed by fitting sheep with re-entrant cannulas in the proximal duodenum and giving them, at each feeding frequency, rations differing in the particle size of the roughage component.

2. Frequent feeding resulted in a less variable daily pattern of flow of digesta and a significant increase $(P<0.0 \mathrm{r})$ in the total daily volume flowing to the duodenum. Altering the particle size of the ration did not affect the flow of digesta at either feeding frequency.

3. The pattern of flow of dry matter followed very closely that of the flow of digesta, but there was a significant $(P<0.001)$ interaction between feeding frequency and particle size of the ration which affected the flow of starch to the duodenum. As a result, more starch entered the duodenum when both the frequency of feeding and the particle size of the ration were increased.

In previous work (Thompson \& Lamming, 1972) it was shown that under carefully controlled conditions the experimental procedures imposed upon sheep during the measurement of digesta flow to the duodenum had no effect on the results obtained. A $24 \mathrm{~h}$ experiment involving total collection of duodenal contents in a well-trained sheep, accustomed to the experimental conditions, can therefore be expected to yield reliable results without the need to correct flow-rates for the recovery of an inert marker. In the previous work the particle size of the ration had a significant effect on the flow of starch to the duodenum, and it was decided to study this further.

Preliminary investigations suggested that, though the pattern of flow of starch to the duodenum might have been affected by the frequency of feeding, the amount of starch which escaped fermentation in the rumen daily was unaltered by increasing the feeding frequency from once to three times per d. Although many workers have studied the effect of altering the feeding frequency on the pattern and total daily flow of digesta (Hogan \& Phillipson, 1960; Ash, 196r; Singleton, 196r; Harrison \& Hill, 1962; Pickard, 1971), there are no published results on the effect of frequency of feeding on the flow of starch to the duodenum.

The present work formed part of a study designed to investigate the use of pulverized straw in ruminant rations. When this system is used in commercial practice it is the usual convention to feed the animals $a d l i b$., and it was considered desirable, therefore, to assess the effect of frequent feeding on the extent of digestion anterior to the duodenum.

The present paper reports studies comparing the effect of two different feeding

- Present address: Rumenco Ltd, Stretton House, Burton-on-Trent, Staffs. 
frequencies on the flow of digesta, dry matter, and starch to the duodenum of sheep over a 24 h period, when given two rations that previously (Thompson \& Lamming, 1972) had significantly affected the flow of starch to the duodenum.

\section{EXPERIMENTAL}

Sheep and housing. Two 2-year-old cross-bred castrated male sheep (nos 3 and 4), weighing approximately $50 \mathrm{~kg}$, and fitted with re-entrant cannulas in the proximal duodenum (Thompson \& Lamming, I972) were used. They were penned individually under conditions of even temperature $\left(15^{-1} 8^{\circ}\right)$ and continuous lighting.

Feeds and feeding. The composition of the rations has been given by Thompson \& Lamming (1972). In this study the sheep were given $900 \mathrm{~g}$ of either ration $\mathrm{B}$ (chopped straw and pelleted cereal diet) or ration $\mathrm{C}$ (pelleted, ground straw and cereal diet) once daily at 09.00 hours or in twenty-four equal hourly feeds. When either the ration or the feeding frequency was changed at least 3 weeks were allowed for the sheep to adapt to the new regimen. Water was available to the sheep at all times.

Sampling and analysis of digesta. The method of collection and the analyses carried out on the digesta have been described by Thompson \& Lamming (1972).

Experimental design. 'Two $24 \mathrm{~h}$ experiments were conducted on each sheep on each feeding regimen to measure the flow of digesta to the duodenum. These were generally $7 \mathrm{~d}$ apart and after the second experiment the feeding regimen was changed. The two sheep were on the same regimen simultaneously when experiments were conducted for we have observed that the activity of one animal can be influenced by the activity of the adjacent animal.

\section{RESULTS}

Total daily volume of digesta. The total daily volume of digesta entering the duodenum of two sheep given $900 \mathrm{~g}$ of either the chopped-straw ration or the groundstraw ration either once daily or in twenty-four equal hourly feeds is shown in Table 1. There was no significant difference between the mean flow on either ration, but the mean flow was significantly $(P<0.0 r)$ higher when the sheep were fed twenty-four times per $\mathrm{d}$. There was no significant difference in the performance of either sheep.

Total daily dry matter. The total daily amounts of dry matter flowing to the duodenum of these sheep are also given in Table r. Again there was no significant difference between the mean flow on either ration or in either sheep, but there was a significant increase $(P<0.01)$ in the flow of dry matter when the frequency of feeding was increased from once to twenty-four times per $d$. There was no significant difference between the mean dry-matter contents of the digesta on any treatment.

Total daily starch. The total amounts of starch flowing to the duodenum per $\mathrm{d}$ are also presented in Table $\mathbf{I}$.

The mean daily flow of $23.6 \mathrm{~g}$ starch when the sheep were given the ground-straw ration once daily was significantly lower $(P<0.001)$ than the $45^{\circ} 3,43^{\circ} \mathrm{O}$ and $47^{\circ} .4 \mathrm{~g}$ starch flowing to the duodenum on the other three treatments. There was also a significant difference $(P<0.01)$ between the performances of the two sheep, there 
Vol. 30

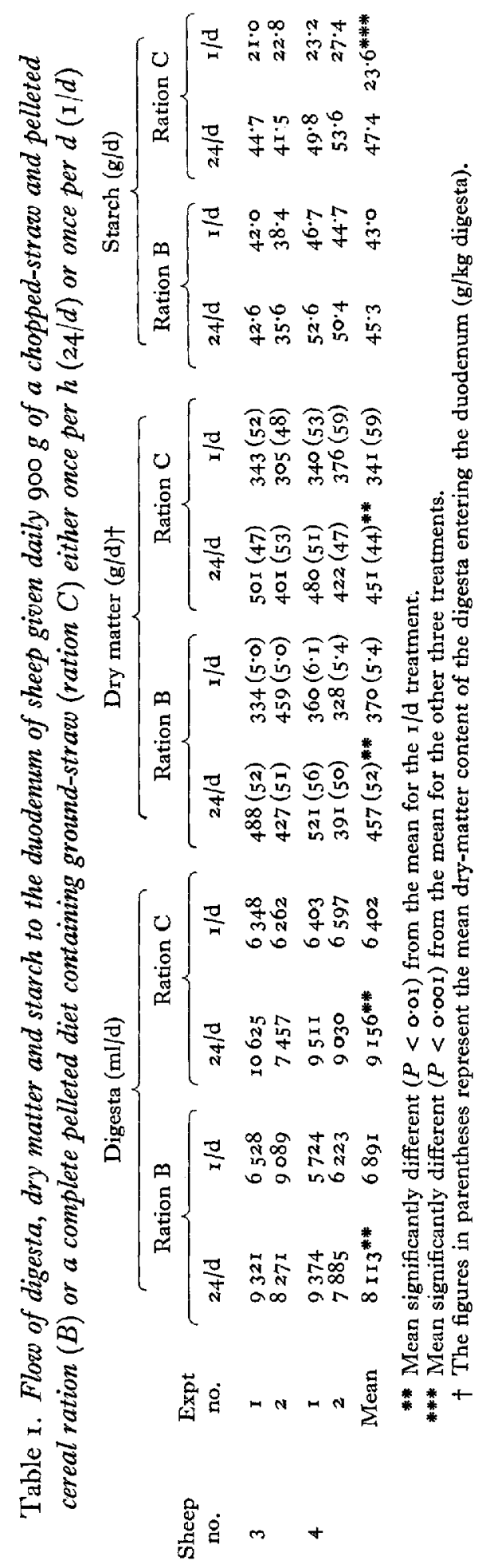



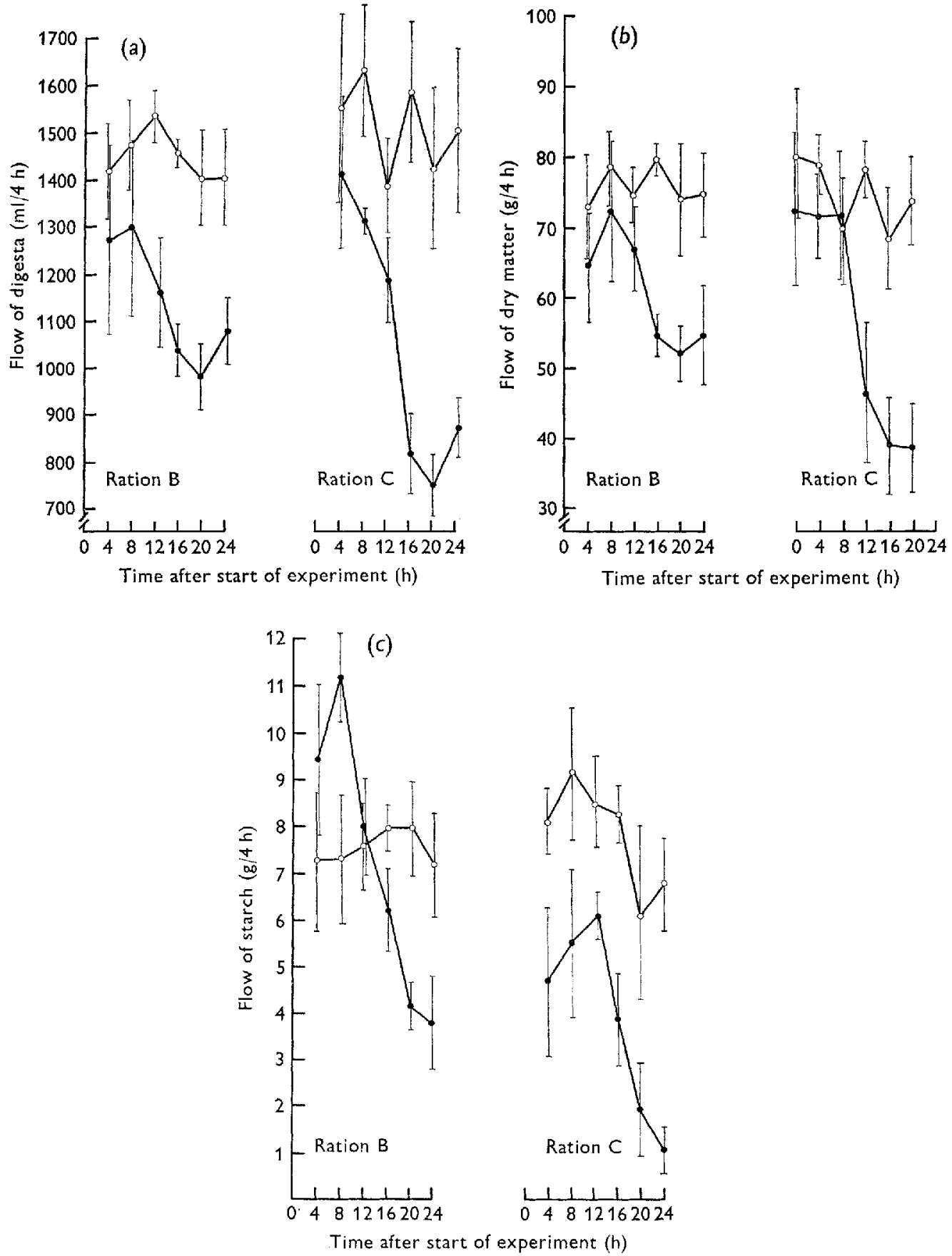

Fig. 1. Patterns of flow of $(a)$ digesta, $(b)$ dry matter and $(c)$ starch to the duodenum of sheep when given daily $900 \mathrm{~g}$ of a chopped-straw and pelleted cereal ration (B) or a complete pelleted diet containing ground straw (ration $C$ ) either once per d (C-O) or in twenty-four equal hourly feeds $(\mathrm{O}-\mathrm{O})$. The vertical bars represent the standard errors of the mean values calculated from results of two experiments on each of two sheep. 


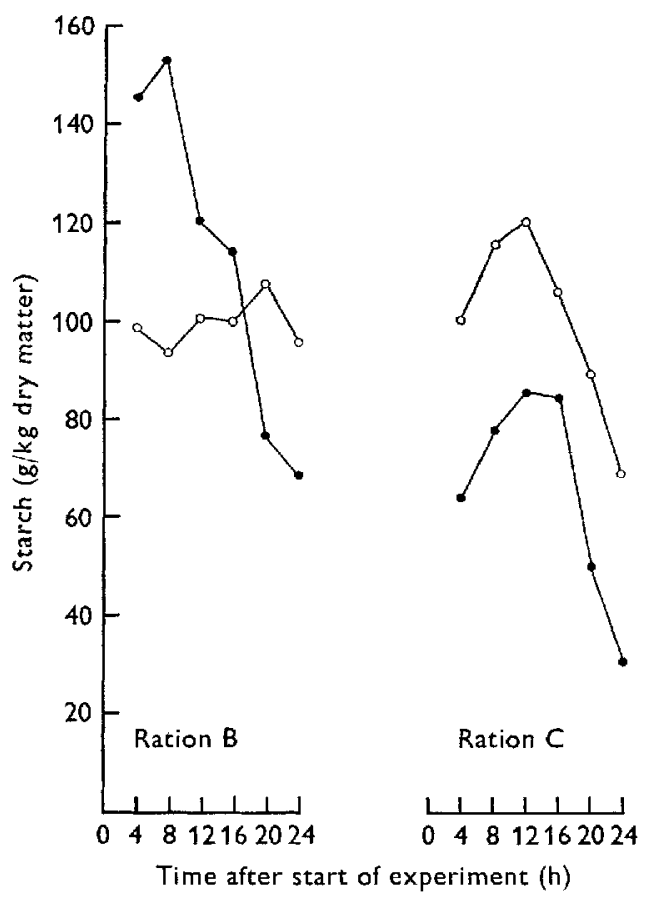

Fig. 2. Changes over $24 \mathrm{~h}$ in the amount of starch in duodenal dry matter of sheep when given daily $900 \mathrm{~g}$ of a chopped-straw and pelleted cereal ration (B), or a complete pelleted diet containing ground straw (ration $\mathrm{C}$ ) either once per $\mathrm{d}(\mathbf{O}-\mathbf{)}$ ) or in twenty-four equal hourly feeds $(\mathrm{O}-\mathrm{O})$.

being more starch present in duodenal digesta collected from sheep no. 4 (mean, 43.6 $\mathrm{g} / \mathrm{d}$ ) than from sheep no. 3 (mean, $36 \cdot \mathrm{r} / \mathrm{d}$ ).

Pattern of flow of digesta and dry matter over $24 \mathrm{~h}$. The patterns of flow of digesta and dry matter to the duodenum over a $24 \mathrm{~h}$ period when the sheep were given $900 \mathrm{~g}$ of the chopped-straw ration or the ground-straw ration either once per $\mathrm{d}$ or in twentyfour equal hourly feeds are shown in Figs $\mathrm{r} a$ and $\mathrm{I} b$. Each point on the graph represents the volume of digesta or the amount of dry matter flowing to the duodenum over a $4 \mathrm{~h}$ period and is the mean for two experiments on each of two sheep (i.e. four values).

The patterns of flow of digesta, and of dry matter, were affected by the frequency of feeding of the sheep. There was an increase in flow after feeding, and a peak was reached either $4 \mathrm{~h}$ (ground-straw ration) or $8 \mathrm{~h}$ (chopped-straw ration) after the single feed was eaten. When the sheep were fed in twenty-four equal hourly feeds throughout the day, the pattern of flow was much more even over the $24 \mathrm{~h}$ and there was not a distinct, diurnal rhythm. There was greater variation in the pattern of flow, at both feeding frequencies, on the ground-straw ration than on the chopped-straw ration.

Pattern of flow of starch over $24 h$. The basic patterns of flow of starch are given in Fig. I $c$ and are similar to those observed for the flow of digesta; that is, the more frequently the sheep were fed, the less variable was the flow to the duodenum. When the ground-straw ration was given once per $d$ the flow of starch to the duodenum was 
Table 2. Average daily $p H$ of duodenal digesta in sheep given daily goo $g$ of a choppedstraw and pelleted cereal ration $(B)$ or a complete pelleted diet containing ground-straw ration $(C)$, either once per $h(24 / d)$ or once per $d(\mathrm{I} / d)$

\begin{tabular}{|c|c|c|c|c|c|}
\hline \multirow[b]{2}{*}{ Sheep no. } & \multirow[b]{2}{*}{ Expt no. } & \multicolumn{2}{|c|}{ Ration B } & \multicolumn{2}{|c|}{ Ration C } \\
\hline & & $24 / d$ & $I / d$ & $24 / \mathrm{d}$ & $\mathrm{I} / \mathrm{d}$ \\
\hline 3 & $\begin{array}{l}I \\
2\end{array}$ & $\begin{array}{l}2 \cdot 4 \mathrm{I} \\
2 \cdot \mathrm{I} 4\end{array}$ & $\begin{array}{l}2.53 \\
2.55\end{array}$ & $\begin{array}{l}2 \cdot 26 \\
2 \cdot 23\end{array}$ & $\begin{array}{l}2 \cdot 12 \\
2 \cdot 20\end{array}$ \\
\hline 4 & $\begin{array}{l}\text { I } \\
2\end{array}$ & $\begin{array}{l}2 \cdot 90 \\
2 \cdot 76\end{array}$ & $\begin{array}{l}2 \cdot 85 \\
2 \cdot 81\end{array}$ & $\begin{array}{l}2.57 \\
2.69\end{array}$ & $\begin{array}{l}2.95 \\
2.80\end{array}$ \\
\hline
\end{tabular}

very much smaller than with the other treatments, since there was not a large peak in starch flow in the hours just after feeding.

The proportion of starch in the dry matter flowing to the duodenum also affects the total amount of starch that flows to the duodenum. The changes in the starch content of the dry matter over a $24 \mathrm{~h}$ period are given in Fig. 2.

An average of $6.6 \%$ starch was present in the dry matter collected from the duodenum when the sheep were given the ground-straw ration once per $d$. This was much lower than the average for the other treatments, which was $10.4 \%$ for the groundstraw ration given twenty-four times per $\mathrm{d}, \mathrm{I} \mathrm{r} \cdot 4 \%$ for the chopped-straw ration given once per $\mathrm{d}$ and $10.0 \%$ for the chopped-straw ration given twenty-four times per $\mathrm{d}$.

More frequent feeding with the chopped-straw ration resulted in less variation in the proportion of starch in the dry matter. With the ground-straw ration, however, the pattern of change over $24 \mathrm{~h}$ was similar for both feeding frequencies, reaching a peak about $12 \mathrm{~h}$ after the start of the experiment.

Duodenal $\mathrm{pH}$. The average $\mathrm{pH}$ values of the duodenal digesta throughout the $24 \mathrm{~h}$ periods are also given in Table 2. There was no significant difference between the mean daily $\mathrm{pH}$ on either ration or at either feeding frequency, but the mean $\mathrm{pH}$ of the duodenal digesta of sheep no. 3 was significantly $(P<0.01)$ lower than that of the other sheep.

\section{DISCUSSION}

The amount of digesta which flowed to the duodenum per $d$ when the sheep were fed once per $d$ was consistent with results obtained by Harrison \& Hill (1962), Pickard (1971) and Thompson \& Lamming (1972) and the increase in the flow of digesta with an increase in the frequency of feeding supports the findings of Harrison \& Hill ( 1962 ). However, the increase in the mean hourly flow of digesta observed in this study from $277 \mathrm{ml} / \mathrm{h}$ on once per $\mathrm{d}$ feeding to $372 \mathrm{ml} / \mathrm{h}$ on the hourly feeding regimen was not so large as that reported by Harrison \& Hill (r962). Since these workers measured the flow for only $7 \mathrm{~h}$ periods, it is possible, as they themselves recognized, that the large differences observed between the mean hourly flows on once per $d$ and three times per $\mathbf{d}$ feeding did not persist throughout the whole day.

The steady pattern of flow of digesta obtained when the sheep were fed once per $h$ agrees with that reported by Hogan \& Phillipson (1960), Ash (196r), Singleton (1961), 
Bruce, Goodall, Kay, Phillipson \& Vowles (1966) and Pickard (1971) when sheep were fed either twice or three times per $d$. The pattern observed when the sheep were fed once per $\mathrm{d}$ was very similar to that previously reported by Thompson \& Lamming (1972).

Pickard (1971) observed a steady pattern of flow when sheep were fed three times per $\mathbf{d}$ which changed to one in which up to $65 \%$ of total daily flow occurred in the first I2 $\mathrm{h}$ when the feeding regimen was changed to one feed/d. Gradually the sheep became 'accustomed' to the new regimen and the flow returned to a steady pattern throughout the day. He did not, however, report any difference in total daily flow of digesta with different feeding frequency. Campling, Freer \& Balch (I96r) observed that cattle fed $a d l i b$. had similar weights of dry matter in the rumen immediately before a feed, irrespective of diet. They explained the different voluntary intakes of hay and straw in terms of different rates of removal of material from the alimentary tract, which ensured that this constant critical level was reached before feeding. From these findings Pickard (1971) postulated that when sheep were changed to a less frequent feeding regimen their rumens were emptied at a fast rate shortly after the feed was consumed in anticipation of further feeds. When the feed was not offered, the rate of flow declined and the total daily digesta flow was unaltered, suggesting that the rate of flow from the rumen is regulated by the expected frequency of feeding.

In this study, however, although the sheep were given at least 3 weeks to adapt to a new regimen, the pattern of flow of digesta was different at the different feeding frequencies, and on the once-daily regimen resembled Pickard's (1971) 'unaccustomed' flow pattern. It is considered unlikely that the sheep were not fully adapted to any of the treatments, and it is therefore difficult to explain this difference in the results.

An explanation of the increase in flow of digesta to the duodenum with more frequent feeding may be easier to find. The extra time spent eating by sheep on the hourly feeding regimen probably results in the production of a greater volume of saliva, and the acceleration of the flow of digesta postulated by Pickard (1971), in anticipation of a further feed, may have resulted in digesta leaving the rumen before complete fermentation occurred, which would account for the increased flow of dry matter to the duodenum.

At a feeding frequency of once per $d$ there was significantly less starch present in duodenal digesta when the sheep were given the ground-straw ration compared with when they received the chopped-straw ration, an observation which is in agreement with the results of Thompson \& Lamming (1972). However, feeding the sheep at a frequency of once per $h$ resulted in the flow of similar amounts of starch to the duodenum per $\mathrm{d}$ on both rations. It appears, therefore, that an increase in the frequency of feeding increased the amount of starch which escaped rumen fermentation only when the sheep received the ground-straw ration. The increase in the flow of starch to the duodenum that occurred when the frequency of feeding of the ground-straw ration was increased can be explained by the increase in the flow of digesta and dry matter to the duodenum. Since there was an increase in the starch content of the duodenal dry matter as well as an increase in total dry-matter flow as a result of feeding the ground-straw ration more frequently, it appears that there was a greater increase 
in the rate of passage of the cereal particles than in that of the straw particles of the ration. This may have been due to a difference in the physical properties of the two components; for instance, the slowness of the straw to hydrate and its low specific gravity are both factors that would prejudice its rapid passage from the rumen.

Since an increase in the particle size of the ration has already been shown to increase the rate of flow of cereal particles from the rumen (Thompson \& Lamming, 1972), increasing the frequency of feeding of the chopped-straw ration may have increased the rate of flow of other dietary constituents from the rumen, resulting in an increase in the total dry-matter flow and a slight decrease in the percentage of starch in the dry matter, so that roughly similar amounts of starch flowed to the duodenum daily.

There was no significant effect of the particle size of the roughage component of the diet, nor the frequency of feeding on the $\mathrm{pH}$ of duodenal digesta.

The author acknowledges the assistance of Mr R. Mawson and Miss V. Attenburrow for help with the flow measurements and the help of Professor G. E. Lamming during the preparation of this manuscript. The work was completed during tenure of a Meat and Livestock Commission Scholarship and the project was supported by a grant in aid from the Agricultural Research Council.

\section{REFERENCES}

Ash, R. W. (196r). Y. Physiol., Lond. 156, 93.

Bruce, J., Goodall, E. D, Kay, R. N. B., Phillipson, A. T. \& Vowles, L. E. (1966). Proc. R. Soc. B $166,46$.

Campling, R. C., Freer, M. \& Balch, C. C. (1961). Br. F. Nutr. 15, 53 I.

Harrison, F. A. \& Hill, K. J. (1962). \%. Physiol., Lond. 162, 225.

Hogan, J. P. \& Phillipson, A. T. (1 g60). Br. F. Nutr, 14, 147.

Pickard, D. W. (197I). The use of ground roughage in the nutrition of ruminants. PhD Thesis, University of Nottingham School of Agticulture.

Singleton, A. G. (rg6r). F. Physiol., Lond. 155, r 34 .

Thompson, F. \& Lamming, G. E. (1972). Br. F. Nutr. 28, 39 I. 